\title{
Practical dimension of urban and regional resilience concepts: a proposal of resilience strategy model
}

\begin{abstract}
It is not only growth and development that is of value to local, regional and central governments, but also the ability to absorb negative phenomena and the ability to continuously transform socio-economic systems. Resilience strategies thus serve as a response to the more and more frequent and intense natural, social and economic challenges. In some approaches to urban resilience, special attention is paid to activities undertaken by cities to become inclusive, integrated, robust, resourceful, reflective, redundant and flexible. In regional strategies the emphasis is on diversity, dispersion, mutuality and modularity. The aim of the paper is to synthesise selected qualities of resilient cities and regions into a new model of resilience strategy. It assumes that goals at each level of strategy are formulated according to adaptive interpretation of the resilience concept. Development of such model would enable the use of the concept by practitioners responsible for creating development strategies.
\end{abstract}

Keywords

Resilience $\cdot$ urban strategy $\cdot$ regional strategy $\cdot$ resilience model

(c) University of Warsaw - Faculty of Geography and Regional Studies
Grzegorz Masik ${ }^{1}$, Maja Grabkowska $\circledast^{2}$

'Department of Socio-Economic Geography, Institute of Geography, University of Gdansk, Gdańsk, Poland

e-mail: grzegorz.masik@ug.edu.pl

${ }^{2}$ Department of Socio-Economic Geography, Institute of Geography, University of Gdansk, Gdańsk, Poland

e-mail: maja.grabkowska@ug.edu.pl.

Received: 31 May 2019

Accepted: 1 October 2019
Introduction

In the era of global change urban and regional resilience have become important buzzwords. They allow the evolutionary process of how the socio-economic system adapts to changing external conditions to be described and make it possible to examine cities and regions in a dynamic, holistic and systematic way-the so-called complex adaptive systems (Davoudi 2013; Simmie \& Martin 2010). The concept of resilience takes into account determinants of development, including the economic dimension (economic resilience; Martin 2012; Martin \& Sunley 2015; Plummer, Tonts \& Argent 2018) but also, to a large extent, the social dimension (social and community resilience; Adger 2000; Obrist, Pfeiffer \& Henley 2010; Norris et al. 2008; Quinlan et al. 2016) and the institutional dimension (agency perspective; Bristow \& Healy 2014; Masik 2018).

According to different interpretations of resilience, i.e. engineering, ecological and adaptive (Simmie \& Martin, 2010; Boschma 2015; Martin \& Sunley 2015), it is assumed that resilience is defined by the ability of socio-economic systems to withstand shocks and to adapt, as well as overcome, difficult post-crisis situations (Xiao, Boschma \& Andersson 2017). In the research on resilience the importance of an external factor (crisis) and its destructive effects on a city or region are emphasized; however, both of these elements can likewise be seen as a chance to renew and transform inefficient socio-economic systems (Gong \& Hassink 2017).

The adaptive interpretation of resilience-a perspective pointing to continuous evolution-is an approach which explains the causes of the resilience of localities, regions or states, the manner in which these systems can be modified, and the ways in which they adapt to change. Goldstein et al. $(2015$, p. 1287) indicates that the essence of adaptive resilience is "an ability to change as circumstances change, to adapt and [where appropriate, to] transform". Three types of system reactions are most frequently distinguished, although they may also constitute shock reaction stages: persistence (resisting disturbance and maintaining the status quo), transition (adaptation) and transformation (change) (Meerow, Newell \& Stults 2016). Moreover, these three categories apply to capacities of resilient systems: absorptive coping, adaptive and transformative capacity (Béné et al. 2012; fig. 1).

The concepts of urban resilience and regional resilience differ slightly in terms of research and scale. One of the definitions of the former states that urban resilience "refers to the ability of an urban system-and all its constituent socioecological and socio-technical networks across temporal and spatial scales - to maintain or rapidly return to desired functions in the face of a disturbance, to adapt to change, and to quickly transform systems that limit current or future adaptive capacity" (Meerow, Newell \& Stults 2016, p. 39). This rationale shows that the resilience of cities is not only explained by the systemic but the evolutionary approach as well. Attention is paid to elements of the system and its functions, and to three essential features that allow cities to be resilient, i.e. the ability to change, adapt and constantly transform. Furthermore, it is emphasized that building resilience is most effective when it involves a mutual and responsible network of civic institutions, agencies and individual citizens working together to achieve common goals under a common strategy (Coaffee et al. 2018).

In turn, regional resilience is defined as an "ability of a region to anticipate, prepare for, respond to, and recover from 


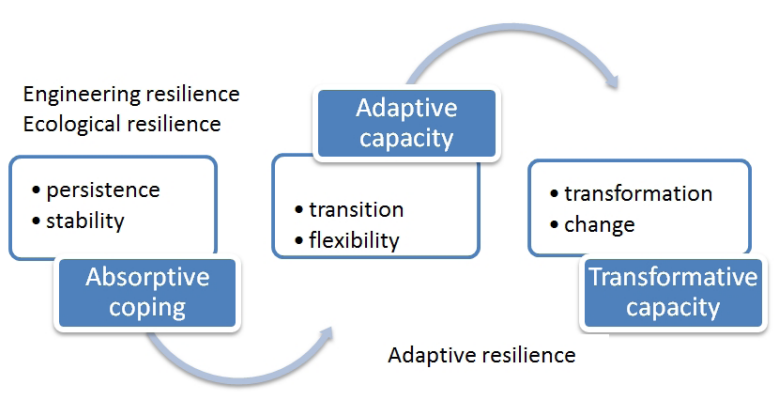

Figure 1. The response model of the socio-economic system to external shock. Source: own elaboration based on Béné et al. (2012) and Meerow, Newell \& Stults (2016)

a disturbance" (Foster 2007, p. 14). This definition draws attention to the actions taken by the institutions in response to an external shock. Martin (2012) distinguishes four interrelated dimensions of regional resilience: resistance, recovery, reorientation and renewal. These coincide with the evolutionary approach and assume that resilience amounts to a region's ability to resist external negative impulses, but also to rebuild, change and adapt its internal structures under the influence of internal impulses. In contrast to urban resilience, regional resilience studies are carried out under the equilibrium approach (Pendall, Foster \& Cowell 2010), within the framework of engineering interpretation, where equilibrium is a point toward which the region should strive.

Against the theoretical background of the above definitions of urban and regional resilience as well as their adaptive interpretation, the aim of this paper is to present a new approach for strategy building on the basis of the concept of resilience. In particular, the authors intend to demonstrate specific components of urban and regional strategies and the structure of the goals of the resilience strategy model. This model has applicational value and may be especially useful to local and regional governments in vulnerable socio-economic systems planning to implement resilience strategies.

Urban resilience strategy and the resilient city

The concept of resilience has become increasingly popular among academics and practitioners alike. One of the most important global undertakings to put it into practice is the "100 Resilient Cities" initiative implemented by the Rockefeller Foundation (100 Resilient Cities 2019). Aimed at creating development strategies for resilience in four dimensions-institutional, economic, social and environmental-the initiative involves one hundred cities around the world. The main conclusion drawn from the elaboration of the project was that for a city to become more resilient, the resilience strategy should be robust, redundant, flexible, resourceful, reflective, inclusive and integrated (Mexico City 2019). Robustness guarantees that the strategy is developed through a clear, rigorous process that brings together accepted quantitative and qualitative approaches. Redundancy assumes that cities have the capacity to address different challenges. Flexibility means that the strategy should be adaptable to unpredicted changes and situations. Therefore, the resilience strategy should be periodically updated. Resourcefulness requires the strategy to take the resource restrictions of a given city into consideration and to look for innovative solutions to overcome them. The quality of reflectiveness refers to changes based on lessons learned and constant reevaluations based on real-time data. Inclusiveness stands for the ability to attract different stakeholders, including those who are the most vulnerable to shocks, to ensure transparency and collective responsibility. Lastly, an integrated strategy combines parts of existing initiatives.

The presented qualities may be classified into three groups according to the phase which they relate to. While the first two refer to pre-existing conditions and prevention, the middle three concern response and recovery and are outcome-oriented, with the last two being process-oriented (Arup 2016). At the same time, features of a resilience strategy mirror the features of a resilient city, which should therefore adapt easily to surrounding and continuous changes, but also be characterized by connectivity, diversity, efficiency and interdependence (Hess 2013; Drobniak 2015). Urban adaptability is expressed by a high level of entrepreneurship and social activity and a high level of innovation. Connectivity means that the city should have active social networks and economic ties. A diverse city has diverse economic specializations and a diverse community. The economic effectiveness of a resilient city involves over-localized competitiveness of the products and services offered. A city's interdependence means that it makes use of good practices and standards in the field of cooperation with other cities and assures complementarity of local services and industries (Drobniak 2015). These attributes of a resilient city should be the goal of a resilience strategy.

\section{Regional resilience strategies}

In regions, which are larger socio-economic systems than cities, more attention is paid to the role of regional authorities as organizers of contacts or platforms for information exchange between cities and the central government and between cities and social and economic organizations. In addition, the objectives of regional strategies and authorities that help build regional resilience are distinguished. These objectives follow Bristow (2010)'s categories: diversity, dispersion, mutuality and modularity.

Diversity means that regions should strive for a high degree of diversification of production, institutions (Bec, Moyle \& Moyle 2018) and energy resources. It also means that supply chains should be dependent on regional enterprises. Dispersion, in the strategy of regional resilience, assumes a greater share of local ownership and control over business, energy suppliers and strategic resources (Davies 2011) than commonly found in economies. Moreover, the region's authorities should seek to increase the number of small-scale companies, i.e. relatively flexible firms. Mutuality stands for a strong emphasis on territorial justice and on the social empowerment of the region's inhabitants, including development of social networks. Modularity translates into greater self-sufficiency in the case of economic or environmental shocks. It also denotes a strong degree of international and intra-regional networking in order to share information, risk and learning (Bristow 2010). The characteristics of a resilient strategy and a resilient city or region are shown in figure 2 .

The key to the success of regional resilience by making it dispersed, mutual and redundant is a policy that fosters a strong regional innovation system, institutions that support the "continuous learning of the region", modern and efficient infrastructure, talented, innovative and entrepreneurial employees and a financial support system providing cheap, longterm loans called patient capital (Christopherson, Michie \& Tyler 2010). It is also important to have control and management functions and a developing R\&D sector (Masik 2018). In summary, two types of structural factors are distinguished that shape regional resilience (Norris et al. 2008, Martin 2012, Palekiene, Simanaviciene, Bruneckiene 2015): inherent capabilities, i.e. the economic structure of the region, innovation system, skills base and level of competitiveness; and adaptive capabilities, i.e. a combination of actions and decisions taken by leaders and institutions that are necessary for a quick return to the development path after the crisis. 
Hierarchization of goals in resilience strategies

The starting point for building a resilience strategy is not to define whether the city or region is resilient, but what level of resilience one wants to achieve. This should be calculated on the basis of the frequency and strength of previous and possible future shocks (Figueiredo, Honiden \& Schumann 2018). When building a resilience strategy, its goals should be given the right priority. Each lower-order goal is just one of the possible ways to achieve a higher-order goal. For example, the overall goal of improving resilience can be divided into four lower-level goals, i.e. building institutional, economic, social and environmental resilience. Economic resilience can be built by diversifying the economy, increasing the level of innovation, increasing the number of

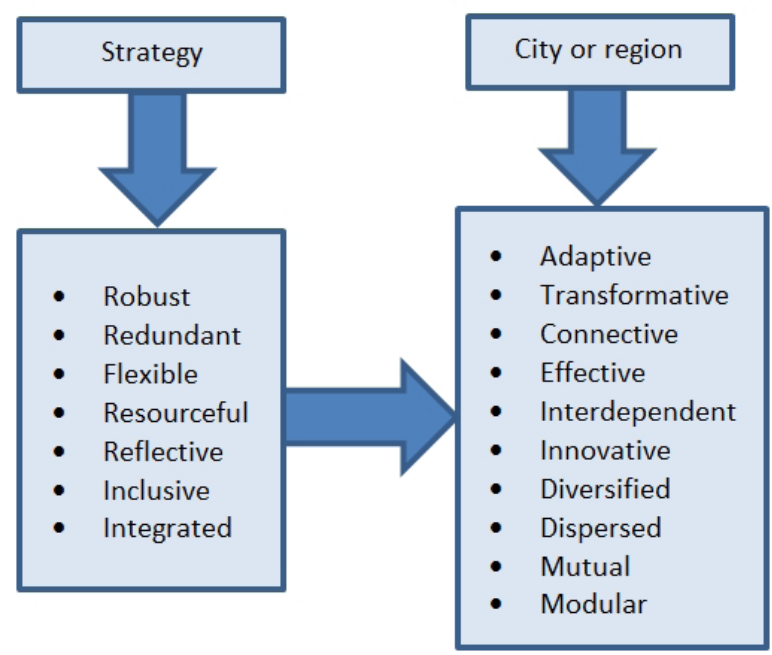

Figure 2. Qualities of resilience strategies and resilient socioeconomic systems. Source: own elaboration based on Bristow (2010), Béné et al. (2012), Drobniak (2015) and Arup (2016) destinations for the export of goods and services, etc. Achieving the goal of a diversified economy, can be done through lowerlevel goals such as increasing the number of small companies in different branches, increasing expenses for employee training in new niche industries, etc. Each goal should have a minimum of two lower-order goals (Figure 3 ).

Figure 3 is only one example of building a resilience strategy model, which should be created by each city or region individually. In order to keep the illustration simple and legible, only the "economic resilience" thread has been developed in detail but this shouldn't be any more prominent than the other three. Institutional resilience can refer to effective leadership and management, empowered stakeholders and integrated development planning. Social resilience can be built by nurturing a collective identity and mutual support, comprehensive security and a rule of law. Environmental resilience can be described by reduced exposure and fragility, and effective provision of critical services (Arup 2016).

In order to increase the degree of operationalization of a resilience strategy, relevant indicators should be included. Performing the role of tools allowing the goals indicated in the strategy to be achieved and to create an evidence base from which better policies can be built (Schumann 2016), they should not be regarded as objectives themselves. Therefore, the pursuit and achievement of a goal should be verified through a panel of experts and practitioners within focus groups or using the Delphi technique (Jordan \& Javernick-Will 2013).

Achieving goals should be monitored during the implementation of the strategy. Indicators should be compared within a given city or region in relation to earlier periods, but not in relation to other cities or regions. Since different cities may have different goals due to different conditions, strategy building requires the creation of context-specific indicators with public participation. When different indicators are adopted, so the target or intermediate value of the indicators may differ. It is also important that the indicators are set at the beginning of the process of strategy building (Figueiredo, Honiden \& Schumann 2018).

An example of institutional resilience indicators could be

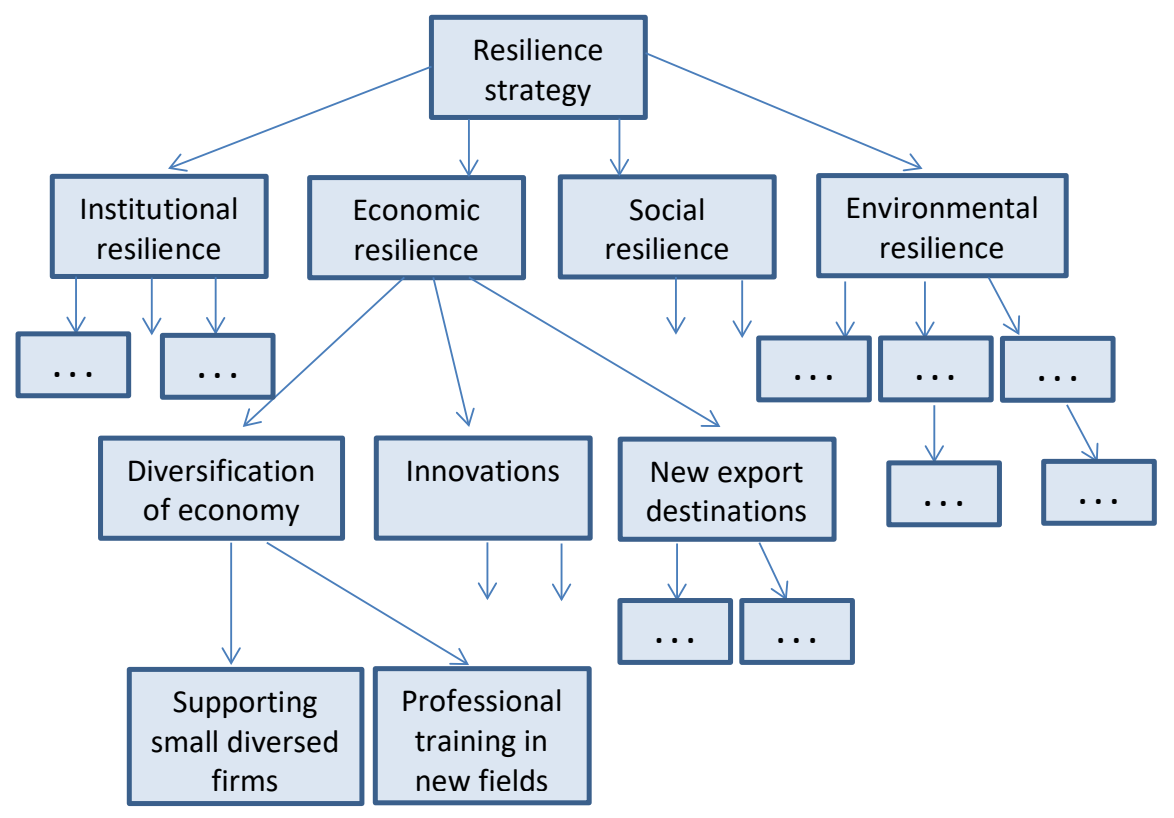

Figure 3. Hierarchical model of resilience strategy (with particular emphasis on economic resilience). Source: own elaboration based on Figueiredo, Honiden \& Schumann 2018 
land use plans developed with reference to a relevant hazard risk assessment, and with the participation of all concerned and transparent government involvement during the process in which policies or plans are drawn up. Economic resilience can be measured by the proportion of the value of small-scale industries out of the total of all industry and by the share of employment in the R\&D sector. In order to measure social resilience, the following indicators can be used: long-term unemployment, the Neet ratio, disposable household income or spatial segregation. Finally, environmental resilience can be measured by the length of a new flood protection barrier, the area for which environmental protection plans have been developed, or the time required for a city to evacuate in the event of a storm.

\section{Conclusion}

The concept of resilience refers to three basic interpretations: engineering, ecological and adaptive. According to the first interpretation, an important feature of cities and regions with regard to external shocks is that they should be able to resist disturbance and maintain the status quo. The second interpretation assumes they reach other levels of balance in many dimensions after a crisis. The third interpretation refers to evolutionary geography, and assumes a continuous process, i.e. adaptation to new circumstances and constant transformation. Within this framework, attributes of adaptive socio-economic systems are formulated. Therefore, it is of key importance for building resilience strategies in cities and regions.

Urban resilience strategies are aimed at strengthening certain characteristics of urban systems. These strategies should therefore be robust, redundant, flexible, resourceful, reflective, inclusive and integrated. Thanks to these attributes, the city strengthens its ability to become more adaptive, transformative, connective, effective and interdependent. Similar strategic actions are taken to build regional resilience. On the other hand, it is more often indicated that a resilient region should be innovative, diversified in terms of economic and social structure, dispersed, mutual and modular. Studies also point to such important determinants of resilience of socio-economic systems as access to natural resources; financial capital; high-quality human capital, including entrepreneurship; and social capital, including cooperation in connected networks.

A review of the studies suggests that all four dimensions, i.e. institutional, economic, social, and environmental resilience are important for building regional resilience. In each of these dimensions lower-order goals should be defined, which allow the strategies to be implemented in an orderly and hierarchical manner. In order to measure the goals, appropriate indicators should be set. The proposed model assumes that the adaptive resilience concept is employed at each of the goals' levels. Yet, the lower the level of defining objectives, the stronger its practical expression. This is so because these goals (such as supporting small diversified companies or professional training in new fields) refer to local or regional governments' activities and describe direct actions as opposed to more general goals, e.g. diversification of the economy, innovations, etc. Thus, the resilience strategy model has operational and applicational value and can be directly implemented by local and regional authorities. The operational value of the model is the possibility of using the discussed concept to build resilience of cities and regions in four dimensions. More practical and defined lower-level goals with monitoring indicators provide the application value of the proposed model.

\section{ORCID}

Grzegorz Masik (1) http://orcid.org/0000-0001-6019-7763

Maja Grabkowska (D) https://orcid.org/0000-0001-9155-8621

\section{References}

100 Resilient Cities, 2019. Available from: <https:/l www.100resilientcities.org/>. [13 April 2019].

Adger, WN 2000,' Social and ecological resilience: are they related?' Progress in Human Geography, no. 24, pp. 347-364.

Arup and The Rockefeller Foundation 2016, City Resilience Index: Understanding and Measuring City Resilience. Available from: <https://www.arup.com/perspectives/publications/ research/section/city-resilience-index>. [18 April 2019].

Bec, A, Moyle, ChJ \& Moyle, BD 2018, 'Community Resilience to Change: Development of an Index', Social Indicators Research, vol. 142, no. 3, pp. 1103-1128.

Béné, Ch, Wood, RG, Newsham, AJ \& Davies M 2012, 'Resilience: New utopia or new tyranny? Reflection about the potentials and limits of the concept of resilience in relation to vulnerability reduction programmes', IDS Working Papers, vol. 2012/405, pp. 1-61.

Boschma, R 2015, 'Towards an evolutionary perspective on regional resilience,' Regional Studies, vol. 49, no. 5, pp. 733-751.

Bristow, G 2010, 'Resilient regions: re-'place'ing regional competitiveness', Cambridge Journal of Regions, Economy and Society, no. 3, pp. 153-167.

Bristow, G \& Healy, A 2014, 'Regional resilience: An agency perspective', Regional Studies, no. 48, pp. 923-935.

Christopherson, S, Michie, J \& Tyler, P 2010, 'Regional resilience: Theoretical and empirical perspectives', Cambridge Journal of Regions, Economy and Society, no. 3, pp. 3-10.

Coaffee, J, Therrien, MC, Chelleri, L, Henstra, D, Aldrich, DP, Mitchell, CL, Tsenkova, S \& Rigaud, E 2018, 'Urban resilience implementation: A policy challenge and research agenda for the 21st century', Journal of Contingencies and Crisis Management, vol. 26, no. 3, pp. 403-410.

Davies, S 2011, 'Regional resilience in the 2008-2010 downturn: Comparative evidence from European countries', Cambridge Journal of Regions, Economy and Society, no. 4 , pp. 369-382.

Davoudi, S 2013, 'Resilience: A bridging concept or a dead end?', Planning Theory and Practice, no. 13, pp. 299-307.

Drobniak, A 2015, 'Koncepcja urban resilience: narzędzie strategicznej diagnozy i monitoringu miast [The concept of urban resilience: a tool for strategic diagnosis and monitoring of cities], Ruch Prawniczy, Ekonomiczny i Socjologiczny [Legal, Economic and Sociological Movement], vol. LXXVII, no. 1, pp. 119-143.

Figueiredo, L, Honiden, T \& Schumann, A 2018, 'Indicators for resilient cities', OECD Regional Development Working Papers, no. 2018/02, OECD Publishing, Paris.

Foster, KA 2007, A case study approach to under-standing regional resilience, Berkeley, University of California, Institute of Urban and Regional Development.

Goldstein, BE, Wessells, TA, Lejano, R \& Butler, W 2015, 'Narrating resilience: Transforming urban systems through collaborative storytelling', Urban Studies, no. 52, pp. 12851303.

Gong, H \& Hassink, R 2017, 'Regional resilience: The critique revisited' in Creating resilient economies: Entrepreneurship, growth and development in uncertain times, eds N Williams \& T Vorley, Edward Elgar, Cheltenham, pp. 206-216.

Hess, D 2013, 'Sustainable consumption, energy and failed transitions: The problem of adaptation' in Innovations 
in Sustainable Consumption. New Economies, Sociotechnical Transitions and Social Practices, eds MJ Cohen, $\mathrm{H}$ Szejnwald Brown \&PJ Vergragt, Edwartd Elgar Publishing, Cheltenham, pp. 159-178.

Jordan, E \& Javernick-Will, A 2013,'Indicators of community recovery: Content analysis and Delphi approach', Natural Hazards Review, vol. 14, no. 1, pp. 21-28.

Martin, R 2012, 'Regional economic resilience, hysteresis and recessionary shocks', Journal of Economic Geography, vol. 12, no.1, pp. 1-32.

Martin, RL \& Sunley, PJ 2015,'On the notion of regional economic resilience: Conceptualisation and explanation', Journal of Economic Geography, no. 15, pp. 1-42.

Masik, G 2018,'An agency perspective of resilience: the case of Pomorskie region, European Planning Studies, vol. 26, no. 5, pp. 1060-1077.

Meerow, S, Newell, JP \& Stults, M 2016, 'Defining urban resilience: A review', Landscape and Urban Planning, no. 147, pp. 38-49.

Mexico City, 2019. Available from: <https://100resilientcities.org/ strategies/mexico-city/>. [13 April 2019].

Norris, FH, Stevens, SP, Pfefferbaum, B, Wyche, KF \& Pfefferbaum, RL 2008, 'Community resilience as a metaphor, theory, set of capacities, and strategy for disaster readiness', American Journal of Community Psychology, no. 41, pp. 127-150.

Obrist, B, Pfeiffer, C \& Henley, R 2010,'Multi-layered social resilience: a new approach in mitigation research', Progress in Development Studies, vol. 10, no. 4, pp. 283-293.

Palekiene, O, Simanaviciene, Z \& Bruneckiene, J 2015, 'The application of resilience concept in the regional development context', Procedia - Social and Behavioral Sciences, no. 213, pp. 179-184.

Pendall, R, Foster, KA \& Cowell, MM 2010,'Resilience and regions: Building understanding of the etaphor', Cambridge Journal of Regions, Economy and Society, no. 3, pp. 71-84.

Plummer, P, Tonts, M \& Argent, N 2018, 'Sustainable rural economies, evolutionary dynamics and regional policy', Applied Geography, vol. 90, pp. 308-320.

Quinlan, AE, Berbés-Blázquez, M, Haider, LJ \& Peterson, GD 2016, 'Measuring and assessing resilience: broadening understanding through multiple disciplinary perspectives', Journal of Applied Ecology, no. 53, pp. 677-687.

Schumann, A 2016, 'Using outcome indicators to improve policies: Methods, design strategies and implementation', OECD Regional Development Working Papers, no. 2016/02, OECD Publishing, Paris.

Simmie, J \& Martin, R 2010, 'The economic resilience of regions: Towards an evolutionary approach', Cambridge Journal of Regions, Economy and Society, no. 3, pp. 27-43.

Xiao, J, Boschma, R \& Andersson, M 2017, 'Resilience in the European Union: The effect of the 2008 crisis on the ability of regions in Europe to develop new industrial specializations', Industrial and Corporate Change, vol. 27, no. 1, pp. 15-47. 